\title{
Correction to: Nutritional Ketosis in Parkinson's Disease - a Review of Remaining Questions and Insights
}

\author{
Alexander Choi $^{1} \cdot$ Mark Hallett $^{1} \cdot$ Debra Ehrlich $^{2}$
}

Published online: 26 July 2021

(c) The American Society for Experimental NeuroTherapeutics, Inc. 2021

\section{Correction to: Neurotherapeutics (2021) https://doi.org/10.1007/s13311-021-01067-w}

The title for Fig. 1 has been corrected.

The original article has been corrected.
Publisher's Note Springer Nature remains neutral with regard to jurisdictional claims in published maps and institutional affiliations.

The original article can be found online at https://doi.org/10.1007/ s13311-021-01067-w.

\section{Alexander Choi}

alexander.choi@nih.gov

1 Human Motor Control Section, Medical Neurology Branch, National Institute of Neurological Disorders and Stroke, Bethesda, USA

2 Office of the Clinical Director, Parkinson Disease Clinic, National Institute of Neurological Disorders and Stroke, Bethesda, USA 